http://jmscr.igmpublication.org/home/

ISSN (e)-2347-176x ISSN (p) 2455-0450

crossref DOI: https://dx.doi.org/10.18535/jmscr/v7i11.175

Journal Of Medical Science And Clinical Research

IGM Publication

An Official Publication of IGM Publication

\title{
Role of Pathology laboratory in detecting Sexual assault
}

\author{
Authors \\ Dr Ganesh Kumar ${ }^{1}$, Dr (Prof.) Shailendra Kumar², Dr (Prof.) Ajay Kumar ${ }^{3}$ \\ ${ }^{1}$ Asstt. Prof. (Path.) PMC Dhanbad \\ ${ }^{2}$ HOD Forensic Medicine PMC Dhanbad \\ ${ }^{3}$ Professor (Path.) PMC Dhanbad
}

\begin{abstract}
Sexual assault is prevalent in our society \& is usually unwitnessed \& prosecution needs support of laboratory evidence in the court room. Simple laboratory methods with lapse of time may fail to collect evidences but Better staining techniques, chemical analysis \& applications of molecular pathology are now able to bring positive proof against the assailants in the court room.
\end{abstract}

\section{Introduction}

Sexual assault continues to prevail in our country. The act of Sexual assault is usually unwitnessed, therefore victim's claim of assault needs support of corroborating laboratory evidence. As a pathologist we enter the realm of sexual assault with a definite challenge to examine four areas -

(1) Can we prove sexual contact occurred?

(2) When did the assault occur?

(3) How can we best document our evidence?

(4) Who is the assailant?

With the discovery of better staining techniques (pap stain, chrimas tree stain) chemical analysis \& molecular pathology we are now able to bring our laboratory in the court room \& use our knowledge to bring positive proof against the assailant.

Most cases of sexual assaults especially in adult victims involve penile penetration in to vagina, rectum or mouth. Vaginal penetration occurs in approx $90 \%$ cases. In order to address these areas a knowledge of semen, spermatozoa \& physical examination of collection of lab evidence is crucial.

Ejacualate or semen -

Composed of Seminal Fluid $-60 \%$

Prostatic secretion---------------------20\%

Secretion of bulbourethral glands \& Urethral glands $-15 \%$

Spermatozoa -------------------------05\%

Normal volume of ejaculate is $1.5 \mathrm{ml}$ to $5.0 \mathrm{ml} \&$ contains 60 to 200 million spermatazoa per $\mathrm{ml}$.

Semen is also rich in fructose sugar $(200 \mathrm{mg} / \mathrm{dl})$. Seminal vesical is the source of fructose in semen. This is used by spermatozoa as an energy source Fructose negative may indicate an absence of seminal vesicle, absence of vas deference or an obstruction at the level of seminal vesicle. Diminished level of fructose have been shown in andogen deficiency. Absence of fructose may mean vasdeferens obstruction at or before ejaculatory ducts.

The first fraction of ejaculate is rich in sperms. Prostatic fluid of semer contains Acid phosphatase $\&$ spermine phosphate. 
An elevated level of acid phosphatase is a specific indication of recent intercourse \& ejaculate even in an individual who has undergone a vesectomy, spermatozoa will be absent but the Acid phosphatase will be elevated in the semen specimen from Victim's Vagina, mouth or anorectal area.

Acid Phosphatase level in the Vagina, mouth or anorectal area decrease rapidly over time. (after 8 hrs). The level of Acid Phosphatase remains elevated longer in dried secretions on the extragenital areas beddings or clothings

Another substance pro glycoproteins analysis is a prostatic antigen found in semen even in vasctomised men has become more sensitive test

Spermatozoa- are positive proof of sexual contact \& their presence is strong evidence for prosecution of any sexual assault case. Unfortunately a data analysis of records of pathology lab of P.M.C.H. Dhanbad showed almost $99.9 \%$ negative finding for spermatozoa in investigation of medicolegal cases. A negative finding does not rule out incidence of sexual assault /rape. A search of cause for negative findings revealed-

1) Late Reporting/examination of victim. Generally a saline wet mount of cervico vaginal smear examination can show motile sperm if collected within $3 \mathrm{hrs}$.

After 12 hrs molile sperms are not found in cervico vaginal semers/high vaginal swab swears.

2) Spermatozoa begin to degenerate within hrs after ejaculation. The obvious sign of degeneration is loss of the tail. This loss occurs after $16 \mathrm{hrs}$.

3) Non motile spermatozoa \& spermatozoa heads can be detected in cervico- vaginal smears within $72 \mathrm{hrs}$

4) After 72 hrs rarely spermatozoa are found in cervico - vaginal smears

5) In the rectum sperpmatozoa seen to lose their tails more quickly after 6hrs especially in oral cavity Successful recovery o f of spermatozoa in the rectum can occur up to $24 \mathrm{hrs}$ after ejaculation.

This decreased survival is due to action of saliva \& bacteria in mouth.

6) Positive identification of spermatozoa from Vagina, Anorectum or mouth may be affected by douching, urinating, ingesting oral contraceptive pills, defaecating, mouth washing \& drinking.

7) Prepubertal young girls also have decreased survival in cervico vaginal specimens due to a decreased cervical mucus.

In post pubertal girls spermatozoa may remain in vaginal secrections for 6-12 hrs in cervix for as long as 5 days.

8) The assailant may be vasctomised surgically /may be oligospermic/may be azoospermic.

9) The assailant may use condoms

10) Withdrew before ejaculation or may be sexually dryfunctional

11) Dried secretion on clothing remains stable for longer than $1 \mathrm{yrs}$.

Physical examination \& collection of evidencesLab evidence in sexual assault cases included Vaginal, anorectal or oral swabs, extra genital semen residues, Foreign material such as hair and fibers \& clothing from victim or bedding that could prove as evidence. We prefer sterile cotton swab to collect specimens.

Semen will Fluoresce blue green when exposed to ultra violet light of wood's lamp. If a fluoressecent area is detected a sterite cotton swab moistened with sterile water or saline can be prepared for further analysis.

Search for spermatozoa can prove challenging. A clinical laboratory professional is asked to assist in emergency examination.

Molecular Pathology \& sexual assaults: Absence of a aforementioned evidences i.e. semen \& Spermatazoa does not disprove victim's claim. If spermatozoa are not detected and Acid phosphatase level is not elevated does not mean the sexual assault never took place $\&$ is not 
necessarily due to an error in collection, processing or interpretation of the specimens.

New advances in pathology \& Laboratory medicine have opened the doors for alternative demonstration of positive evidence indicating sexual assault. Two recent technique are (i) FISH (Fluoresent in situ hybridisation \& (2) DNA fingerprinting - These two technique have taken it into realm of science $\&$ technology that we never dreamt possible.

FISh is highly sensitive \& highly specific procedure that uses a DNA probe specific for a chromosome or chromosome region. The probe is labelled with a non radioactive fluorescent molecule \& hybridized to the homolous region in cell DNA studies using FISH \& Y chromosome specific DNA probes have indentified non sperm male cells even when Acid phosphatise are not elevated \& no sperm is present. The assailant's epithelial cells/or inflammatory cells originating from penis and genital tract, from hand or cells from mouth may be identified in semen from victim. This is especially important in cases of child sexual assaults when assault is digital or oral in nature. Even without presence of spermatozoa or elevated Acid phosphatase level we can prove that contact has occurred.

In the 1980 Alec jefferys opened the door of DNA applications in law enforcement. 08,09,10 The DNA double-helix ladder can be cut with restriction enzymes, the fragment analyzed by the southern blot using electrophoresis, and the ladder fragments "unzipped" by denaturation. 9 The fragments are blotted onto a membrane and single strand DNA probes are added. The complementary sites bind, or hybridize, and the membrane is exposed to X-Ray film. When the film is developed, we have dark bands showing the location of the radioactive probes. The appearance is like a barcode, and this is our fingerprint. Next, we look for bands from the known sample to match with bands from the evidence. For example, we can compare the bands from the suspect assailant's DNA with the bands from a vaginal swab (evidence). We take into account that the female victim's DNA also will appear as bands from the vaginal swab. Because interpretation can be difficult, the entire process is repeated; in most cases three to five different probes are eventually used.

Problems can arise if not enough evidentiary DNA is present for the performance of a southern blot. The technique of polymerase chain reaction, or PCR, was developed and perfected to amplify the DNA by replication. The enzyme used to replicate the DNA is a polymerase. PCR can make millions of copies of a single cell DNA, enough DNA with which to perform a Southern blot. We therefore can match a single hair root, a small drop of blood or semen, or skin cells found under a victim's fingernails to a suspect assailant. The potential that molecular pathology has in the world of forensics is almost limitless. Now, not only can we prove that male cells are present, but also we can examine the DNA in these cells and match them to an individual.

\section{Conclusion}

The Pathology Laboratory with its new techniques \& Skilled observers is at the forefront of the sexual assault investigation. The responsibility of prosecution is great $\&$ lies in our laboratories.

\section{References}

1. Tipple AL, Julian TM, Sexual Assault: the problem and its management. Minn Med. 1984;433-436.

2. Tucker S, Claire E, Ledray L.E, et al. Sexual assault evidence collection. Wis Med J. 1990;20:33-39.

3. Gabby T, Winkleby MA, Boyce T, Sexual Abuse Chilldren: the detection semen on skin. Am J Dis Chil.1992;146:700-703.

4. Willott GM, Allard JE. Spermatozoa- their persistence after sexual intercourse. Forensic Sci Int. 1982;19:135-154.

5. Sharpe N. The significance of spermatozoa in victims of sexul assault. Can Med Assoc J. 1964;89;513-514. 
6. Enos WF, Beyer JC. Spermatozoa in the anal canal and rectum and in the oral cavity of female rape victims. J Forensic Sci 1978;23:231-233.

7. Gill P, Jeffreys AJ, Werret DJ. Forensic application of DNA 'fingerprints'. Nature.1985;318:577-579.

8. Jeffreys AJ. DNA typing : approaches and application. J. Forensic Sci Soc. 1993;33:204-211.

9. Jeffreys AJ, Wilson V, Thein SL, Hypervariable "mini-Satelite" regions in human DNS. Nature. 1985;314:67-73.

10. Jeffreys AJ, Wilson V, Thein SL, Individual- specific "fingerprints" of human DNA. Nature.1985;314:76-79.

11. Chakroborty R, Kidd KK. The utility of DNA typing in forensic work. Science. 1991;254:1735-1739.

12. Gill P, Lygo JE, Fowler SJ, et al. An evaluation of DNA fingerprinting for forensic purpose. Electrophoresis. 1987;8: $38-44$. 